\title{
ESCOLARIDADE E INSERÇÃO NO MERCADO DE TRABALHO
}

\author{
MARIA EUGENIA LETELIER G. \\ Mestre em Sociologia (Universidade Católica do Chile) — Doutora em Educação (PUC-SP)
}

\section{RESUMO}

Este artigo pretende situar a relação entre escolaridade e inserção no mercado de trabalho num período marcado pelo impacto das transformações produtivas (1988 e 1995), a partir da análise de dados do mercado de trabalho e escolaridade da População Economicamente Ativa - PEA — referentes à Grande Santiago (Chile) e Grande São Paulo (Brasil). Considera-se que, nesse período, foi elaborado um discurso que ressaltava o valor econômico da educação, sem suficiente sustentação empírica que ajudasse a verificar como a população é afetada pela dinâmica do mercado de trabalho e pelo aumento da oferta do sistema educacional.

A competitividade internacional como meta é tida como tendência que dificulta a identificação das condições estruturais em que está inserida a relação entre educação e trabalho não permitindo, assim, conhecer a dinâmica dos atores sociais que se confrontam numa sociedade que constrói consensos excludentes em relação a numerosos setores. Para estes um maior nível educacional não assegurará melhores condições de vida enquanto não se modificarem as desigualdades originadas na estrutura do mercado de trabalho, pois justamente nesse período de transformações estão sendo geradas novas segmentações que tendem a aprofundar a desigualdade.

CHILE-MERCADODETRABALHO-BRASIL - RELAÇÕESEDUCAÇÃO-TRABALHO

\section{ABSTRACT}

SCHOOLING AND LABOR MARKET ENTRY. This article discusses the relationship between schooling and entry into the labor market during a period marked by the impact of production transformations (1988 and 1995), analyzing data on the labor market and educational levels of the Economically Active Populations in Greater Santiago (Chile) and Greater São Paulo (Brazil). In this period, a discourse was developed highlighting the economic value of education, but in had insufficient empirical support to help verify how the population is affected by labor market dynamics and increased accessibility of the educational system. As a goal, international competitiveness is viewed as a tendency which makes it difficult to identify the structural conditions in the relationship between education and work. Thus it does not permit us to learn about the dynamics of the social agents who are faced with a society that constructs a consensus which excludes numerous sectors. For persons from the excluded sectors, a better educational level does not ensure improved living conditions if the inequalities deriving from the labor market structure are not modified. It is exactly in this period of transformation that new divisions tending to deepen the inequalities are being generated. 


\section{DESENVOLVIMENTO SUBORDINADO À COMPETITIVIDADE EXTERNA}

Num contexto de transformações produtivas orientadas para conseguir maior competitividade no mercado internacional e de políticas que ressaltam o papel da educação para alcançar a eqüidade, os dados sobre o mercado de trabalho evidenciam que a relação entre nível de escolaridade e renda está debilitando-se, ou seja o nível de escolaridade dos trabalhadores tem, cada vez mais, menor incidência em sua remuneração.

O fato, concomitante ao aumento das desigualdades na distribuição da renda, sugere que a relevância que se outorga à formação dos recursos humanos, como fator-chave para o alcance de melhor inserção no mercado de trabalho internacional, coloca em primeiro plano a relação entre economia e educação, esquecendo ou constrangendo os sujeitos sociais a esta relação.

As importantes diferenças nos níveis de escolaridade da população economicamente ativa, entre regiões urbanas de países latino-americanos que sofrem o impacto dos processos de reestruturação e o significativo aumento da escolaridade da população para o conjunto das atividades e ramos produtivos, assinalam que as exigências do mercado de trabalho, relativas à educação, estão associadas ao nível geral alcançado pela sociedade. Isso enseja o debate sobre a oferta da mão-de-obra escolarizada e sua relação com as demandas do mercado de trabalho. Em outras palavras, deseja-se saber se essa relação se define com base em um novo perfil nos níveis de educação da sociedade e/ou nas exigências das transformações produtivas que demandam trabalhadores com maior escolaridade.

A literatura ressalta o aumento das exigências de qualificação da mão-de-obra como uma das características que assinalam a diferença entre um paradigma produtivo, antes orientado para um trabalho repetitivo e fragmentado, e um paradigma que requer criatividade, autonomia e trabalho em equipe. A mesma literatura, fundamenta-se, substancialmente, em estudos de caso, em pesquisas nos postos de trabalho, nas fábricas e em determinados ramos produtivos.

O sistema educacional, por outro lado, estabelece seu ideário de reformas, em estreita relação com a idéia global de competitividade, buscando atender as exigências do mundo do trabalho com planos que abrangem uma formação ampla em detrimento de formações específicas, consideradas inadequadas ao momento produtivo atual. Os sujeitos — alunos e professores que ensinam e aprendem — parecem subordinados às exigências de um modelo que, antes de atender suas necessidades e motivações mais amplas em relação à educação, supõe que eles devem servi-lo.

Assim, se por um lado a centralidade da educação está situada como um discurso macrossocial em que a globalização e a competitividade são seus argumentos e os sujeitos sociais estão subordinados a eles, por outro, as novas exigências educacionais de um paradigma emergente evidenciam-se em pesquisas realizadas em determinadas fábricas ou ramos produtivos, das quais se inferem orientações gerais que, em certas ocasiões, constituem as evidências para se estabelecer o que deve ser ou não aprendido e/ou ensinado. 
As análises que, durante estas duas últimas décadas, têm acompanhado a relação entre educação e trabalho, têm como ponto de partida as exigências que se colocam para o sistema educacional, mas são poucas as que se propõem a conhecer o impacto e as redefinições que os processos de reestruturação produtiva realizam sobre o mercado de trabalho, para, com base nisso, definir o papel que a educação poderia vir a ter. Nesse sentido, o consenso alcançado sobre a necessidade de uma ampla educação de qualidade pode encobrir a falta de consumo gerada pelos processos de transformação do trabalho. Depois de décadas de planejamento estruturado dos recursos humanos, na atualidade não parece haver objetivos e procedimento claros e adequados para qualificar a força de trabalho.

\section{AS TRANSFORMAÇÕES VISTAS A PARTIR DA ANÁLISE DOS DADOS}

A modernização e reestruturação produtiva é um processo desenvolvido com diferentes estratégias e ênfases, que embora tenha como elemento comum a inserção na economia internacional - impactada pelos acelerados avanços tecnológicos - adquire especificidades que são resultado tanto dos processos históricos e sociais dos países como das orientações políticas com que estas transformações foram desenvolvidas.

Os dados que analisaremos dizem respeito a dois mercados urbanos de trabalho inseridos em países distintos da América Latina, no período de 1988 a 1995, que se encontram em etapas diferentes do processo de reestruturação.

Chile, assinalado como um "modelo", é considerado o único país da América Latina em que foi superada a primeira etapa do ajuste e reestruturação produtiva. Diferentemente de outros países da região que adotaram uma estratégia gradual, no Chile, a reestruturação foi radical e intensa, o que significou um prolongado e alto custo social para o país'. Desde 1988, embora os indicadores evidenciem forte crescimento econômico, acompanhado de aumento dos índices de emprego, até o momento não se conseguiu superar as fortes desigualdades originadas na distribuição da renda, disparidades que, ao invés de reduzirse, estão acentuando-se².

No Brasil, São Paulo concentra a maior atividade do setor produtivo e de serviços da América Latina. A estratégia de reestruturação, nesse país, está tendo um caráter gradual; iniciou parcialmente a inovação produtiva em alguns ramos e empresas durante a década de oitenta, mas só recentemente, na década de noventa, é que está desenvolvendo políticas de

I. A política de estabilização, simultânea à implantação de reformas e liberalização do mercado, produziu dramáticos efeitos sobre o mercado de trabalho. $\bigcirc$ indicador mais eloqüente é a taxa de desemprego aberto que manteve uma média de $18 \%$ ao mês e a redução das remunerações em $20 \%$, no período de 1974-1982, em comparação com o ano de 1970. Entre 1982 e 1983, a situação agravou-se ainda mais em conseqüência da crise recessiva externa; neste período, o índice de desemprego alcançou um recorde de $30 \%$.

2 Os últimos dados da pesquisa da CASEN - Caracterização Sócio-Econômica Nacional - assinalam que a razão entre a participação na renda dos $20 \%$ mais ricos e dos $20 \%$ mais pobres, em 1987, era de treze vezes; já, em 1996, esta proporção é de quatorze vezes. 
abertura externa ${ }^{3}$. Como conseqüência do aumento da intensidade da reestruturação produtiva e da abertura comercial durante o período que analisaremos, o mercado de trabalho apresenta grandes transformações caracterizadas pelo aumento do desemprego, redução de postos de trabalho na indústria e precarização das condições de trabalho para um significativo número da população.

A informação que sustenta nossa análise, para o caso de São Paulo, provém da Pesquisa de Emprego e Desemprego - PED - realizada pela Fundação Sistema Estadual de Análise de Dados - SEADE. Para o caso de Santiago, a fonte de dados é a Encuesta Nacional de Empleo - ENE -, feita no Chile pelo Instituto Nacional de Estadística - INE.

Tais fontes de informação nos oferecem uma visão da escolaridade alcançada pela População Economicamente Ativa - PEA - e das características do mercado de trabalho. A associação entre as diferentes variáveis, permite-nos ressaltar características e tendências que fundamentam a análise.

Perfil educacional da sociedade explica demanda educacional do mercado de trabalho

Os dados de escolaridade da PEA indicam que estamos diante de duas regiões com ofertas educacionais bastante diferentes. Em 1995, a Grande Santiago tinha 70\% da PEA com nove ou mais anos de escolaridade, enquanto que na PEA da Grande São Paulo, apenas $40 \%$ se encontravam nessa mesma faixa. Porém, diferenças como essas, não impediram, até o momento, que o processo de industrialização da Grande São Paulo mostrasse um dinamismo muito maior que o de Santiago.

Segundo o discurso dominante, o mercado de trabalho está demandando uma mãode-obra mais escolarizada para o desempenho no trabalho. Porém, se fosse certa esta afirmativa, deveria estar ocorrendo um certo grau de homogeneidade em determinadas ocupações. Entretanto, quando associamos anos de estudo a categorias correspondentes da estrutura do mercado de trabalho, os dados mostram que a escolaridade não é uma condição determinante para o desempenho de certas funções, o que questiona a hipótese.

Os exemplos são muitos. Tomando por referência o ano de 1995, em São Paulo, $46 \%$ dos motoristas tinham quatro anos ou menos de escolaridade; em Santiago apenas 3\% estavam nesse mesmo intervalo. Em São Paulo, 37\% das telefonistas e operadoras de telecomunicações tinham o segundo grau completo ou mais, já para Santiago essa percentagem elevava-se a 70\%. Em São Paulo, a média de escolaridade para as enfermeiras e parteiras, em 1995, era de 9,4 anos de estudo; em Santiago, para essa mesma categoria, era de । I,7

3. $\bigcirc$ processo que marca esta mudança é o denominado Plano Collor, apoiado no trio liberalização, desregulamentação e privatização que, com a reformulação das políticas industriais e de comércio exterior, instaurou uma nova fase de estratégias empresariais de grande impacto sobre a produtividade e a competitividade do sistema produtivo. 
anos. Em São Paulo, a média de escolaridade para eletricistas e operadores de aparelhos de som era de 6,9 anos de estudo; já para Santiago, a média elevava-se a 10,7 anos. Em São Paulo, a média de escolaridade para despachantes e carteiros era de 6,8 anos de estudo, enquanto para Santiago, a média era de 10,9 anos.

Esses exemplos de profissões que, a rigor, não requerem habilidades muito diferentes, permitem-nos afirmar que a relação entre escolaridade e inserção no mercado de trabaIho está determinada pelo perfil educacional geral alcançado pela sociedade, mais do que pela demanda de qualificação oriunda do mercado de trabalho.

Tais dados demonstram que a mão-de-obra precisa cada vez mais de maiores graus de escolaridade, não porque sejam necessários para desempenhar as funções demandadas pelo posto de trabalho, mas, principalmente, para competirem em melhores condições por um emprego. A educação passa a ter valor como fator de competição também no mercado de trabalho do próprio país.

É relevante analisarmos os dados do setor industrial moderno. Em 1995, para Santiago esse setor compreendia 7\% do total da PEA; em São Paulo, a percentagem elevava-se a 13,5\%. É interessante observar que São Paulo, com um menor nível de escolaridade, alcançou maior desenvolvimento da indústria moderna. Nesta última região, 58\% da PEA ocupada na indústria moderna tinha, naquele ano, oito ou menos anos de escolaridade, enquanto para Santiago a percentagem era de 25\%. Torna-se relevante ainda comprovar que em Santiago, na indústria metal-mecânica, não se registraram casos com escolaridade básica incompleta, enquanto em São Paulo, 42\% da PEA não havia concluído o primeiro grau.

É certo afirmar que existem condicionamentos históricos que explicam por que o setor industrial se desenvolve com independência da oferta educacional. Porém, a ênfase colocada na formação dos recursos humanos como fator-chave para alcançar uma competitividade internacional - baseada no aumento da produtividade e da superação da exploração de recursos humanos e naturais - esquece ou pelo menos secundariza esta ótica de análise.

A preponderância que adquire o tema educacional e as exigências de maior investimento social e individual em educação, deslocam o foco do problema ao atribuir à educação a solução de problemas que têm suas origens em condições estruturais e históricas, cuja superação excede tanto a suas funções quanto a suas possibilidades.

Mais escolarização, menos postos de trabalho

A expansão educacional registrada em ambas as regiões faz parte de uma tendência observada em toda a América Latina. Desde os anos sessenta, numerosos estudos comprovam que essa expansão ocorreu com relativa autonomia do sistema produtivo, gerando conhecidos processos de subutilização de mão-de-obra, com a conseqüente frustração das aspirações que a população vem depositando na elevação dos níveis educacionais para a conquista de melhores postos de trabalho. 
No ano de 1988 em Santiago a PEA tinha uma média de 9,7 anos de estudo concluídos. Em 1995 a pontuação subiu para 10,7 anos. Em São Paulo, a tendência é semelhante; verificase que, em 1988, a PEA tinha uma média de 6,7 anos de estudo concluídos; em 1995, aumentou para 7,6. Em sete anos, os ganhos educacionais absolutos marcam uma tendência indiscutível e praticamente igual para as duas regiões. $\bigcirc$ sistema educacional está oferecendo, cada vez mais, ao mercado de trabalho, recursos humanos com maior nível de escolaridade.

As mudanças da estrutura do mercado de trabalho não estão acompanhando a expansão educacional. Quando observamos as transformações nesses sete anos, comprovamos que no caso de São Paulo os postos de trabalho do setor industrial diminuíram de 32,5\% para $25 \%$, aumentando o emprego nos setores ligados aos serviços, especialmente os pessoais, que como já se sabe, é um ramo de atividade que se caracteriza por absorver a população de baixa escolaridade.

A estrutura do mercado de trabalho em Santiago não sofreu mudanças tão bruscas, refletindo de certa maneira a estabilidade conseguida depois do período de ajuste; porém os empregos na indústria não aumentaram. Em 1988 a indústria de transformação absorvia $21 \%$ da PEA e sete anos depois a percentagem elevou-se ${ }^{4}$ em apenas 1\%. Embora tenha crescido o nível de emprego no setor de serviços financeiros, da construção civil e do comércio, o setor de serviços pessoais continua absorvendo aproximadamente 30\% da PEA.

Segundo o que se observa nessa estrutura produtiva, a força de trabalho está estudando mais, porém não necessariamente está encontrando melhores postos de trabalho. Analisando os dados da construção civil, um setor que tradicionalmente concentra a população de baixa escolaridade, verifica-se que em 1988 Santiago tinha 61\% dos trabalhadores com oito ou menos anos de escolaridade. Entretanto em 1995 essa percentagem reduziu-se a 51\%. Em São Paulo, no ano de 1988, 70\% da PEA que trabalhava nesse setor, tinha quatro ou menos anos de escolaridade; já em 1995 essa percentagem reduziu-se a 64\%. Quando se observa o setor de serviços pessoais a tendência é a mesma.

Os dados indicam que os setores que empregam menores percentagens da PEA são os que abrigam a população mais educada. Em Santiago, por exemplo, o setor de serviços financeiros absorve os 9,8\% da PEA que têm em média quatorze anos de estudo. Em São Paulo os serviços sociais, que absorvem $9 \%$ da PEA, e o governo, que absorve $3 \%$ da PEA, são os dois setores que apresentam níveis de escolaridade mais elevados (10,9 anos de estudo em 1995).

Essa segmentação do mercado de trabalho mostra que, em termos absolutos, a estrutura ocupacional emprega efetivamente a população altamente escolarizada em atividades

4. Esses dados refletem o tipo de crescimento alcançado pelo Chile, baseado na abertura econômica externa que está sendo dinamizado pelas exportações em setores de recursos naturais nos quais o Chile tem vantagens comparativas (cobre, celulose, farinha de peixe, produtos agroindustriais) e em setores de produção industrial, baseados em recursos naturais (papel, móveis e madeira, salmão, sucos). 
produtivas que absorvem percentagens pequenas da PEA. Embora o restante da população aumente consideravelmente o nível de escolaridade, não tem com isso asseguradas novas e melhores formas de inserção no mercado de trabalho. A população de baixa escolaridade teria de fazer um grande esforço para que a escolaridade possibilitasse uma mudança efetiva na posição que ocupa atualmente.

Numa perspectiva social, não deixa de ser preocupante que nossas sociedades estejam investindo em educação e não estejam gerando novos postos de trabalho de melhor qualidade e produtividade, subutilizando, assim, a mão-de-obra. A realidade não é nova na América Latina, porém a novidade é a associação quase causal que hoje se faz entre educação e aumento da produtividade. Com isto não só se atribuem à educação funções que excedem a sua finalidade, como também são ocultadas ou distorcidas as exigências de mudanças do próprio sistema produtivo para alcançar maior produtividade.

\section{A modernização produtiva no setor industrial acentua \\ a heterogeneidade no mercado de trabalho}

Todos os dados sobre mercado de trabalho demonstram o crescente deslocamento do emprego industrial para o setor terciário. Esse processo ocorre de maneiras diferentes em cada realidade, obedecendo os fatores históricos e as estratégias de reestruturação adotadas nos países e regiões. Apesar dessa tendência, a indústria continua sendo o lugar em que, principalmente, acontece o progresso técnico e no qual deverá ocorrer o crescimento da produtividade para ser difundida para o conjunto da economia.

No caso de Santiago houve uma diminuição da produtividade no setor industrial $(-3,1)$ e permanece estável o emprego no setor. Essa característica do modelo de desenvolvimento suscita dúvidas sobre a possibilidade que teria o Chile de passar a uma "segunda etapa exportadora", baseada no aumento do valor agregado dos produtos para o mercado externo e interno.

Para São Paulo, a partir de 1991, registra-se um aumento na produtividade industrial que não vem acompanhada da recuperação do emprego no setor. Embora tenha havido uma incorporação de novas tecnologias, estas ainda não foram difundidas entre os elos das cadeias produtivas para o conjunto da economia e/ou estão tendo efeitos negativos no mercado de trabalho.

Em São Paulo a diminuição do emprego industrial foi drástica para os setores modernos. Quando comparadas as diferenças de escolaridade entre 1988 e 1995, observa-se que os ocupados no setor moderno industrial, em relação ao setor tradicional, tiveram um aumento maior nos anos de estudo. No entanto, a estratégia de modernização industrial que está sendo desenvolvida em São Paulo produz dois processos simultâneos: a redução de ocupação e a demanda de mão-de-obra com maior grau de escolaridade. Ambos contribuem para aumentar a heterogeneidade. 
Em Santiago o emprego permanece estável, tanto no setor moderno quanto no tradicional. Porém, ao comparar 1988 e 1995, observamos que se elevou de maneira expressiva a escolaridade no setor industrial tradicional, indicando, portanto, que, em um país com abundante oferta de mão-de-obra escolarizada e com um limitado processo de modernização industrial, não houve necessidade de modificar o perfil educacional da mão-de-obra para o setor industrial.

A falta de trabalho e/ou a intensificação e extensão da jornada

A Grande São Paulo apresenta um elevado índice de desemprego. Em 1995, a taxa de desocupação total era de 12,5\%. Sete anos antes o desemprego alcançava 8,8\% da PEA. Durante o mesmo período aumentou em $6 \%$ a percentagem da PEA que trabalha 35 horas ou menos, aumentando, portanto, o subemprego.

Paralelamente, em São Paulo, a quarta parte dos ocupados trabalha 48 horas e mais, o que evidencia que segmentos importantes continuam expostos a condições de trabalho intensivo, fundamentalmente no setor de serviços pessoais e de comércio.

Durante mais de uma década o mercado de trabalho no Chile foi afetado por fortes níveis de desemprego. Entre 1974 e 1984 a média de desocupação era de 18\% anuais, chegando a um recorde de 30\% em 1983. Superada a etapa de ajuste, houve uma recuperação efetiva da taxa de ocupação, sendo que em 1995 o desemprego em Santiago atingiu 4,4\%.

Aumentou o nível de emprego, mas também aumentou ostensivamente o número de horas de trabalho. Em 1988, 69\% da PEA da região trabalhava 48 horas ou mais; em 1995 a percentagem elevou-se para 78\%. Quando cruzamos essa informação com os anos de escolaridade, a única categoria que mostra uma situação relativamente melhor são os profissionais universitários, dentre os quais apenas $67 \%$ trabalham 48 horas ou mais.

$\bigcirc$ aumento generalizado das horas trabalhadas (legalmente regulamentado) mostra que, uma vez superada a etapa de ajuste estrutural, o modelo consolidado trouxe como conseqüência a intensificação da jornada de trabalho, sendo possível levantar a hipótese de que o crescimento econômico não está alheio a uma sobreexploração da mão-de-obra.

As conseqüências para a vida cotidiana dos trabalhadores evidenciam-se pela invasão do espaço e do tempo dedicado à vida doméstica, no desgaste psicológico e físico dos trabaIhadores, na reprodução cultural dos valores que associam um tempo maior dedicado ao trabalho com aprovação social.

Nas diferentes análises feitas sobre o "modelo chileno" esse é um tema ausente, o qual, porém, afeta de maneira concreta os sujeitos sociais, que novamente são subtraídos da análise ou são considerados apenas em razão dos requerimentos da economia. Essa informação levanta sérias dúvidas sobre a orientação do processo de reestruturação no Chile, o que junto com outros aspetos já assinalados, permite supor que o país está longe de superar a denominada "competitividade espúria", baseada na sobreexploração dos recursos naturais e humanos. 
Diante dessas circunstâncias, é pertinente se perguntar se será esse o caminho traçado para os outros países da América Latina, e que lugar ele ocupa dentro do discurso da eqüidade, no qual a educação é mostrada como uma promissora garantia de sucesso.

desemprego afeta fundamentalmente a população jovem

Durante o período em estudo, tanto em Santiago quanto em São Paulo, o desemprego afetou fundamentalmente a população jovem. Em 1995, para ambas regiões, mais de 60\% dos desempregados tinham 29 anos ou menos de idade.

O desemprego dos jovens nos países da América Latina representa mais do que o dobro das taxas nacionais de desemprego. Essa realidade parece "consubstancial" ao modelo de desenvolvimento atual e a explicação mais freqüente é a falta de educação e formação profissional dos jovens.

Os dados da realidade não sustentam porém essa explicação. As taxas de desocupação dos jovens representam o dobro das taxas dos adultos, qualquer que seja o nível educacional dos indivíduos. Ao analisar os dados diferenciando a média de escolaridade entre os jovens ocupados e desempregados, tanto em Santiago quanto em São Paulo, observa-se que praticamente não existem diferenças; ou seja, a variável escolaridade não explica o desemprego juvenil.

As explicações devem ser buscadas nas condições que o mercado de trabalho oferece aos jovens. Outros estudos sobre o tema (Tockman 1997; Martínez 1997; Escobar 1998; CEPAL 1998) apontam que a maioria dos jovens que entram no mercado de trabalho o fazem de maneira precária. Aqueles que ingressam o fazem fundamentalmente em trabalhos sem proteção, sem contratos e, portanto, sem estabilidade.

As estatísticas disponíveis mostram que os jovens percebem entre I/5 e a metade do que ganham os adultos e que, geralmente, suas rendas são inferiores ao salário mínimo. No Chile, por exemplo, os jovens encontram-se legalmente vinculados a um salário mínimo especial, cujo valor eqüivale a $80 \%$ do salário mínimo legal; até os 21 anos podem ser objeto de uma relação contratual especial, o contrato de aprendizagem. Esse tipo de contrato tem duração máxima de dois anos, não está sujeito ao salário mínimo e os trabalhadores nessa condição estão proibidos de negociar coletivamente.

Dessa maneira a permanência de altas taxas de desemprego juvenil, tanto em épocas de crescimento como de contração econômica, são explicadas pelas condições precárias oferecidas pelo mercado de trabalho. A falta de motivação para aceitar trabalhos de baixa qualidade que não conseguem retribuir seu esforço nem satisfazer expectativas econômicas atuam desestimulando os jovens a incorporar-se no mercado de trabalho.

As políticas destinadas à capacitação de jovens, que surgiram como resposta ao problema do desemprego e as reformas educacionais, especialmente para o $2^{\circ}$ grau, procuram orientar a formação educacional para as demandas de qualificação em profissões mais dinâmicas 
que, potencialmente, poderiam apoiar uma inserção no trabalho em condições mais vantajosas. Porém o sucesso destas políticas está diretamente associado ao ritmo em que o mercado de trabalho gera ocupações de melhor qualidade e melhor renda, capazes de recompensar de maneira justa e adequada os maiores esforços educacionais realizados pelas novas gerações.

Na recessão econômica empregadores privilegiam trabalhadores com maior nível educacional

Em Santiago o perfil de escolaridade da população desempregada tem acompanhado as mudanças gerais da PEA. Em 1988, a média de escolaridade dos ocupados era de 9,7 anos de estudo e para os desempregados de 9,6 anos; em 1995 a média de escolaridade dos ocupados era de 10,6 anos de estudo e a dos desocupados de 10,4.

Em 1995, 50\% dos desempregados tinham doze ou mais anos de estudo concluído. Esses dados indicam que um melhor nível de escolaridade não representa garantia de emprego.

Em São Paulo os dados indicam que não existe uma relação causal entre condição no mercado de trabalho e escolaridade, pois, independentemente dos anos de escolaridade alcançada, importantes segmentos da PEA encontram-se sem trabalho. A informação disponível permite-nos afirmar que os empregadores privilegiam a força de trabalho com maior nível de escolaridade, o que é especialmente válido para a população adulta, a partir dos 25 anos; a estatística aponta que ao estabelecer a diferença entre ocupados e desocupados, os primeiros sempre apresentam um melhor nível de escolaridade. Em situação de retração econômica, os adultos de baixa escolaridade estão mais vulneráveis ao desemprego.

Aumenta a idade da PEA e a taxa de participação da mulher no mercado trabalho

Nos dois mercados de trabalho observa-se a tendência ao envelhecimento da PEA. Diminui o número de jovens e aumenta a percentagem de adultos que permanecem por mais tempo ocupados.

Essa tendência é expressa de maneiras diferentes. Em São Paulo, registra-se uma proporção maior de jovens incorporados ao mercado de trabalho, seja porque as condições econômicas requerem maior colaboração dos filhos para com a família, seja porque a população jovem permanece menos tempo na escola ${ }^{5}$ e/ou porque existam fatores culturais que

5. Indicadores educacionais comparativos que a Organização para a Cooperação e Desenvolvimento Econômico - OCDE - levantou para 43 países, indicam São Paulo como uma das regiões em que as crianças permanecem menos tempo na escola. Apesar de a LDB - Lei de Diretrizes e Bases da Educação - estabelecer que estados e municípios devem se esforçar para aumentar a carga horária até chegar ao tempo integral, os alunos de São Paulo estudam "667 horas por ano, enquanto no Chile os alunos estudam 860 horas por ano" (Folha de S. Paulo, 24 nov. 1998). 
estimulam a incorporação mais cedo ao mercado de trabalho e que permitem também compatibilizar jornadas de trabalho de menor extensão com a continuidade dos estudos.

Em Santiago a população jovem incorpora-se mais tarde ao mercado de trabalho, porém permanece ativa até idades mais avançadas. Esse comportamento também pode estar associado à dificuldade de compatibilizar jornadas extensas de trabalho com o estudo. Entre a população adulta, a legislação trabalhista vigente não permite mais aposentar-se por anos de serviço, apenas por idade.

Nas duas regiões registra-se um aumento da participação da mulher. Em São Paulo, no ano de 1988, a participação da mulher era maior que em Santiago; em 1995, o emprego feminino aí cresceu ainda mais quando comparado a Santiago. Uma característica comum nas duas regiões é que as mulheres, em sua grande maioria, trabalham no setor de serviços, principalmente aquelas com escolaridade mais avançada e recebem uma remuneração ostensivamente menor que a dos homens.

Aumenta a desigualdade na distribuição da renda

Embora se presumisse que as transformações advindas da abertura comercial, das privatizações e da desregulamentação dos mercados gerariam, inevitavelmente, algum custo social, esperava-se que as reformas impulssionassem, no curto e médio prazos, fortes aumentos de produtividade, que dinamizariam a economia no seu conjunto. Nesse marco os setores mais beneficiados pelas reformas gerariam um dinamismo suficiente para absorver, direta ou indiretamente, o desemprego inicial e corrigiriam as iniqüidades derivadas da precariedade nas condições do emprego.

Entretanto, ao analisar os dados da renda provenientes do trabalho, observa-se que nas duas regiões, em momentos diferentes do processo de reestruturação, aumentou a desigualdade na distribuição de renda; esse aumento é ainda maior para o caso de Santiago. ${ }^{6}$

Em Santiago juntamente com o processo de crescimento econômico existe uma recuperação dos salários. Os benefícios do crescimento foram porém distribuídos de maneira desigual. Os dados mostram o ostensivo aumento das diferenças entre os grupos sociais. Em 1988 as diferenças entre os $20 \%$ mais pobres e os 20\% mais ricos eram de 15,3 vezes; sete anos mais tarde, a diferença aumentou para 17,2 vezes. Enquanto para os setores médios diminuiu a capacidade de participação nas rendas, os setores mais pobres conservaram o lugar que sempre tiveram, independentemente de ciclos econômicos.

Em São Paulo os salários experimentaram uma significativa redução. Em 1995, os ocupados percebiam $73 \%$ do que ganhavam em 1988. Interessante observar que, nessa

6. Se tomarmos como referência o coeficiente Gini - índice que mede a distribuição da renda - em Santiago, em 1988, esse era de 0,52, no entanto, para 1995 foi de 0,57. Para o caso da Grande São Paulo, o coeficiente Gini varia de 0,50 a 0,53 . 
situação de retração econômica, se verifica uma tendência semelhante à que ocorre em Santiago. Nessa região, em 1988, a diferença entre o primeiro e o quinto quintil de renda era de 15,5 vezes; em 1995 aumentou para 17,5 vezes. ${ }^{7}$

Os processos de abertura externa, privatização e desregulamentação dos mercados estão marcados por uma acentuada iniqüidade na distribuição de rendas, seja num período de ajuste e recessão, que acontece em São Paulo, seja num período de crescimento e consolidação das reformas como o que está vivendo Santiago.

Os modelos de desenvolvimento que estão sendo implantados em nossos países são marcados por profunda desigualdade social. Nessas circunstâncias vale a pena se perguntar, quais são as reais contribuições que a educação pode oferecer para o alcance de maior eqüidade.

Debilitamento da correlação positiva entre renda e nível de escolaridade

A contradição mais profunda na relação estabelecida entre a valorização da educação e o alcance da eqüidade é comprovar que o aumento dos anos de estudo não se faz acompanhar pela melhoria nas pautas de distribuição de renda, o que traz como conseqüência um debilitamento da correlação entre renda e nível de escolaridade, ou seja, os trabalhadores estudam mais, porém não aumentam o nível de seus rendimentos, tampouco são promovidos a melhores empregos.

modelo tenta suprimir os efeitos negativos do mercado de trabalho direcionando políticas sociais para setores marginais, desenvolvidas com orçamentos insuficientes que não contribuem de maneira efetiva para a melhoria da qualidade de vida. Desloca assim o foco do problema do sistema produtivo - no qual conflitos sociais poderiam ser gerados - para a administração e gestão públicas que, avaliadas com critérios de eficiência e eficácia, passam a ter um papel preponderante para o alcance da eqüidade.

Quando analisamos os dados do mercado de trabalho, tanto em São Paulo como Santiago, ao correlacionar renda com anos de escolaridade observa-se uma mesma tendência.

Para as duas regiões mantém-se uma correlação positiva entre baixa escolaridade e baixa renda. Assim, para o caso de São Paulo, em 1988 e 1995, 40\% dos analfabetos encontravam-se localizados nos dois primeiros decis de renda. Entretanto, para Santiago, em 1988 e 1995, mais de 40\% da população com quatro ou menos anos de escolaridade pertencia aos dois primeiros decis de renda.

À medida que avançamos no nível de escolaridade, observamos que existe uma deterioração nas rendas. Para o caso de São Paulo o problema ocorre principalmente com a população que tem segundo grau completo ou incompleto, que vê aumentada sua participação

7. Cabe indicar que a informação refere-se apenas às rendas provenientes do trabalho. Os dados da Fundação SEADE e do INE não contemplam a medição de investimentos financeiros ou recursos que circulam dentro das empresas sob a forma de investimento de capital, que, igualmente, aumentam o capital individual. Sendo assim, é bastante provável que estejam sendo subestimados os dados de renda para a população mais rica. 
nos intervalos de decis mais pobres, e diminuída nos decis mais ricos. Em 1988, por exemplo, 5, I da PEA que tinha segundo grau incompleto (menos de onze anos de escolaridade) estava no primeiro decil de renda; em 1995, para esse mesmo intervalo, a percentagem eleva-se a 10,2\%. Porém, para o decil mais rico ocorre o contrário; em 1988 17,5\% da PEA com segundo grau completo encontrava-se no decil mais rico; sete anos depois, diminuiu para 12,2\%.

Para o caso de Santiago a deterioração começou para os que têm $2^{\circ}$ grau incompleto. Em 1988, 10,7\% da PEA compreendida nessa faixa de escolaridade encontrava-se no primeiro decil de renda; sete anos mais tarde a percentagem aumentou para 18,2\%. $\bigcirc$ caso mais eloqüente deu-se entre aqueles que têm doze anos completos de escolaridade; em sete anos, observou-se uma acentuada tendência a aumentar as percentagens nos decis mais pobres e a diminuir nos mais ricos, fato especialmente relevante, já que nesse segmento é que está situada a maior concentração de casos, afetando portanto maior contingente da população ocupada.

A deterioração crescente das rendas percebidas pela população com níveis médios de escolaridade indica que a oferta abundante de trabalhadores escolarizados e a escassa expansão de postos de trabalho de melhor qualidade estimulam os empregadores a aumentar as exigências educacionais para a ocupação de postos de baixa remuneração.

O debilitamento da correlação positiva entre escolaridade e renda não acontece só entre a população com escolaridade intermediária. No ano de 1988 em São Paulo, 52,4\% da PEA com estudos superiores pertencia ao decil mais rico da população; em 1995, a percentagem diminuiu para 45,7\%. No mesmo ano, em Santiago 58,5\% da PEA com estudos superiores pertencia ao decil mais rico; em 1995, essa percentagem diminuiu para 43,7\%.

A análise do conjunto das informações demonstra que é cada vez mais freqüente a possibilidade de indivíduos com altos perfis educacionais terem acesso a postos baixos da escala ocupacional. Nesse sentido, a demanda por melhores qualificações e/ou melhores níveis de escolaridade que o processo de reestruturação produtiva estaria estabelecendo, poderia vir a significar um aumento da produtividade ou de crescimento econômico, mas no que diz respeito aos salários, o maior esforço educacional dos trabalhadores não estaria sendo melhor recompensado, no sentido de melhoria na qualidade de vida.

Caso concordemos que o novo paradigma produtivo está demandando um conjunto de comportamentos dos trabalhadores em face das empresas - expressos por valores como confiança, colaboração, responsabilidade, trabalho em equipe - os dados globais evidenciam que a precariedade do mercado de trabalho pode originar conhecidos processos de insatisfação no trabalho, que conspirariam contra os próprios princípios do novo paradigma.

\section{Maior renda para os muito escolarizados e menor dispersão salarial para os demais}

Em São Paulo a perda salarial afeta todos os intervalos de escolaridade. Como já foi demonstrado, a renda percebida por aqueles que tinham quatro anos de escolaridade, em 
1988, é semelhante à recebida, em 1995, pelos ocupados que têm $2^{\circ}$ grau completo. Embora haja uma clara correlação entre aqueles que têm estudos superiores e altas rendas, continua existindo dispersão salarial nos outros intervalos de escolaridade.

Em Santiago a dispersão salarial é menor. Apenas os ocupados que têm uma escolaridade muito acima da média percebem rendas elevadas, indicando, portanto, que em sociedades que alcançaram um maior nível de escolaridade da população existe a tendência a homogeneizar as rendas dos ocupados com escolaridade baixa e intermediária.

Essa concentração da educação contribui para que captem rendas elevadas somente aqueles que podem desempenhar ocupações próprias de tecnologias avançadas. Com essa perspectiva, a educação pode vir a contribuir para agravar o caráter concentrador do modelo.

Diferenças de renda se acentuam nos grupos

ocupacionais independentemente da escolarização

No contexto de crescimento e expansão econômica que vive Santiago, ao comparar renda com níveis de escolaridade e tipo de ocupação, evidencia-se que a concentração da renda está associada a algumas atividades geradas no comércio e, dentro dessas, aos postos de diretores e administradores.

Acontece o contrário para categorias que têm grande importância na PEA, como os trabalhadores de escritório, para os quais observa-se um aumento nos anos de estudo e uma diminuição na capacidade de participar da distribuição da renda.

Um caso especial são os professores, tanto do nível primário como do ensino médio, que, embora aumentem consideravelmente os anos de estudo, têm salários abaixo da média do conjunto da PEA, sendo sua remuneração similar à dos motoristas com um pouco mais da metade dos anos de estudo de um professor. Em São Paulo, ocorre o mesmo que em Santiago. Entre as profissões que mais diminuíram mais sua remuneração e aumentaram o nível de escolaridade, estão os professores. De resto, todas as categorias ocupacionais reduzem ostensivamente seu salário, excetuando apenas uma, os empresários.

Ainda que o discurso público aponte, constantemente, para a importância da reforma educacional como fator-chave para alcançar um crescimento com eqüidade, quando se analisa a informação estatística proveniente do mercado de trabalho, observa-se que na prática existe uma desvalorização da ação educacional.

Velhas idéias num novo contexto?

A análise dos dados anteriores leva-nos, pois, a constatar que a demanda educacional do mercado de trabalho está associada fundamentalmente aos níveis de educação da população; que à reiterada necessidade de qualificar os recursos humanos para alcançar maior competitividade contrapõe-se o fato de uma mão-de-obra que já está sendo subutilizada e 
que, ao lado do discurso que relaciona educação e eqüidade, existe um permanente debilitamento da relação entre renda e escolaridade. Assim, tudo nos faz pensar que as idéias que prevaleceram desde o começo dos anos noventa no campo econômico não podem ser aceitas sem uma revisão crítica.

Já nos anos sessenta, a visão econômica fundamentou a relação entre educação e trabalho. Naquela época, a teoria do capital humano apoiou o argumento de que a educação era fator-chave para o desenvolvimento macrossocial e para as aspirações individuais expressas pelo aumento da taxa de retorno do investimento na educação. Por sua parte, as teorias do planejamento educaciona/fundamentaram a necessidade de formação de recursos humanos em profissões presumidas como indispensáveis para os países subdesenvolvidos, com base nas necessidades manifestas nos países de maior grau de desenvolvimento.

Tais teorias estão configuradas pelo paradigma funcionalista que outorga à educação um papel fundamental para o alcance do equilíbrio social. A educação vista desta maneira atua como geradora de consenso, como "aquela que corrige" os desequilíbrios, e os sujeitos sociais estão subordinados a essa relação de equilíbrio, sem considerar a vontade dos indivíduos/grupos, o jogo de poder e os conflitos entre grupos desigualmente recompensados.

Tampouco são novas as características que ressaltamos a partir da análise dos dados: as incongruências entre estrutura educacional e produtiva, a subutilização da mão-de-obra no mercado de trabalho heterogêneo, a desvalorização do credenciamento educacional, de certa maneira foram as respostas que, a partir dos anos setenta, serviram de argumentação para deslocar a visão econômica preponderante e inserir a educação numa relação social ampla, incorporando a essa a visão o tema dos movimentos sociais, seus interesses e conflitos.

A radicalidade de tais posturas repercutiu nas teorias que colocaram o sistema educacional como um reprodutor da desigualdade social e dos interesses de classe, chegando a afirmar que o sistema educacional era o principal agente ideológico legitimador da sociedade capitalista. Muitas dessas idéias transitaram para o que mais tarde foi chamado de "a nova sociologia da educação", assinalando que a legitimidade do sistema faz-se, em geral, mediante a inclusão de circuitos diferenciados e de segmentação educacional, ou melhor dizendo, por meio de processos de dominação ideológica e/ou simbólica.

Atualmente a interpretação da relação entre educação e trabalho, inclina-se para as teorias econômicas. A força com que tais idéias têm sido defendidas é de tal magnitude que elas têm se transformado em, praticamente, referencial único para o debate e delineamento de políticas. Entretanto, a informação disponível nos permite duvidar de até que ponto conseguirão gerar uma mudança condizente com o que difundem em seu discurso.

Se queremos avançar para uma nova configuração resultante das interações de educação e trabalho em um contexto impactado pelos avanços tecnológicos e pela reestruturação produtiva, é urgente e necessário assumir a complexidade estrutural de nossas sociedades e recolocar os próprios conceitos de educação e trabalho centrando a atenção nos sujeitos e atores sociais, que são finalmente, aqueles que dão vida a essa relação. 


\section{REFERÊNCIAS BIBLIOGRÁFICAS}

CEPAL. Panorama social. Santiago do Chile, 1998.

ESCOBAR, P. Desempleo juvenil. una aproximación al problema. Santiago do Chile: Universidad Arcis, 1998.

FUNDAÇÃO SEADE. Pesquisa de emprego e desemprego - PED: base ano I988. São Paulo, . Pesquisa de emprego e desemprego - PED: base ano 1995. São Paulo,

INSTITUTO NACIONAL DE ESTADÍSTICAS. Encuesta nacional de empleo: base año 1988. Santiago,. . Encuesta nacional de empleo: base año 1995. Santiago,.

MARTÍNEZ, E. Desempleo juvenil en Chile: discriminación o ilusión óptica? Boletín Cinterfor. Montevideo, n. 139-40, p.89-102, 1997.

TOCKMAN, V. El trabajo de los jóvenes en el post-ajuste latinoamericano. Boletín Cinterfor. Montevideo, n.139-40, p.7-23, 1997. 